Mujeres, afectos y estereotipos de género en la desvalorización de los tribunales de menores en Chile, 1928-1968

Women, Affects and Gender Stereotypes in the Devaluation of the Juvenile Courts in Chile, 1928-1968

Femmes, affects et stéréotypes de genre dans la dévalorisation des tribunaux pour mineurs au Chili, 1928-1968

Javiera Errázuriz Tagle y Nicolás Pizarro Huerta

C OpenEdition

Journals

Edición electrónica

URL: http://journals.openedition.org/rhj/7347

DOI: $10.4000 /$ rhj.7347

ISSN: 0719-4153

Editor

ACTO Editores Ltda

Referencia electrónica

Javiera Errázuriz Tagle / Nicolás Pizarro Huerta» « Mujeres, afectos y estereotipos de género en la desvalorización de los tribunales de menores en Chile, 1928-1968 », Revista Historia y Justicia [En línea], 15 | 2020, Publicado el 30 noviembre 2020, consultado el 02 diciembre 2020. URL : http:// journals.openedition.org/rhj/7347 ; DOI : https://doi.org/10.4000/rhj.7347

Este documento fue generado automáticamente el 2 diciembre 2020

Revista Historia y Justicia 


\section{Mujeres, afectos y estereotipos de género en la desvalorización de los tribunales de menores en Chile, 1928-1968}

Women, Affects and Gender Stereotypes in the Devaluation of the Juvenile Courts in Chile, 1928-1968

Femmes, affects et stéréotypes de genre dans la dévalorisation des tribunaux pour mineurs au Chili, 1928-1968

Javiera Errázuriz Tagle y Nicolás Pizarro Huerta

\section{NOTA DEL EDITOR}

Recibido : 29 de abril de 2020 / Aceptado: 28 de julio de 2020

1 A lo largo del siglo XX, el proceso de inserción de las mujeres al mundo del trabajo se amplía y acelera. Distintos oficios y profesiones aparecen como posibilidades nuevas para las mujeres, en una sociedad que se hacía cada vez más compleja y que requería de trabajadores y trabajadoras con mayores conocimientos y cualificaciones.

Esta ampliación de las posibilidades laborales de las mujeres produce grandes debates en torno a cuál es su rol en la sociedad y qué características debía tener el trabajo femenino. Como señala Joan Scott, la mujer trabajadora comienza a ser percibida como un problema que requería una solución urgente. "Este problema implicaba el verdadero significado de la feminidad y la compatibilidad entre feminidad y trabajo asalariado, y se planteó en términos morales y categoriales"'.

Así, por ejemplo, el discurso dominante en las sociedades occidentales de comienzos del siglo XX postulaba que el trabajo de la mujer debía ser excepcional (por ejemplo, por necesidad debido a la muerte o abandono del cónyuge), en actividades específicas y con 
un salario menor al del varón. La justificación para este discurso está en la división sexual del trabajo que construye el liberalismo, estableciendo que los hombres se encargan del trabajo productivo mientras que las mujeres se dedican a las actividades reproductivas. De este modo, la pertenencia a uno u otro sexo incide en "la ubicación diferenciada y desigual de los individuos en distintos ámbitos sociales" ${ }^{2}$. De ahí que el trabajo femenino fuera del hogar se considerara una anomalía y que se entendiera como algo extraordinario y complementario al del varón.

El problema era que la realidad contradecía este discurso. A lo largo del siglo XX cada vez más mujeres ingresaron al mundo del trabajo, aunque lo hicieron por razones diversas. Algunas por necesidad, otras para garantizar su independencia económica o para desarrollar sus propias capacidades. Independientemente de la razón, la gran mayoría de las mujeres trabajadoras de comienzos del siglo XX se encontró en una situación de subordinación que reprodujo la desigual relación de poder que existía a través de la división laboral entre los sexos manifestada en la existencia de actividades, oficios o profesiones femeninos y masculinos ${ }^{3}$.

5 Este "reparto de tareas" está basado en las nociones patriarcales de lo femenino y lo masculino. De este modo, en la división sexual del trabajo "intervino un proceso de construcción social de sentido que definió la feminidad o condición femenina a partir de la maternidad entendida como hecho biológico"4. Al establecer que las características femeninas se relacionan directamente con la maternidad, las mujeres comienzan a ser definidas a partir de las emociones maternales. Así el afecto, la ternura, la dedicación, la entrega a otros, definen a la mujer, frente "a la razón, la agresividad, el interés propio y el individualismo, evocados como epicentro de la masculinidad"5. La naturaleza femenina, entonces, se traduce en habilidades y atributos específicos que harían a las mujeres ser más eficientes en determinados empleos ${ }^{6}$.

6 La división sexual del trabajo produce también una jerarquización de los oficios femeninos y masculinos, que se manifiesta en diversos aspectos, pero particularmente en el salario y en la valoración social. Lo mismo ocurre cuando hablamos de actividades profesionales. Por ejemplo, maestras, visitadoras sociales o matronas, todas profesiones consideradas como femeninas, van a encontrar más espacios de trabajo durante el siglo XX, pero su inserción laboral se hará desde una posición subordinada: la maestra frente al director/inspector; la visitadora social frente al juez; la matrona frente al médico. Lo que hacía a las mujeres particularmente aptas para ejercer estas profesiones era su naturaleza femenina, vinculada, como hemos señalado, a la maternidad y a los afectos. Así, en el discurso patriarcal, la labor de estas profesionales suponía trasladar al ámbito social aquello que las mujeres ya hacían en el ámbito doméstico: la educación de los niños y el cuidado de pobres y enfermos, independientemente de la formación técnica y los estudios requeridos para obtener el título profesional, lo cual conlleva una desjerarquización o minusvaloración ${ }^{7}$ de esas profesiones.

7 Ahora bien, este proceso también se producirá en aquellos oficios o profesiones tradicionalmente considerados como masculinos, a los cuales, a lo largo del siglo XX, comienzan a incorporarse mujeres. Este es el caso del derecho, una profesión que ha sido asociada al poder político y a valores masculinos, como lo racional, lo objetivo y lo abstracto, los cuales serían superiores a lo irracional, subjetivo y particular, valores tradicionalmente asociados con lo femenino. Así, el derecho se entiende desde una perspectiva dual sexualizada (masculino/femenino) y jerarquizada (superior/inferior), generando una identificación entre lo masculino superior y lo femenino inferior. Desde 
esta perspectiva, y como señala Frances Olsen, podemos considerar al derecho como parte del orden patriarcal y de la dominación masculina, ya que esta jerarquización entre lo masculino y lo femenino resulta opresora para las mujeres ${ }^{8}$.

Con todo, si bien el derecho ha estado históricamente dominado por los hombres, esto no quiere decir que sea un ámbito impenetrable para las mujeres. Desde mediados del siglo XX, las mujeres que estudian y ejercen el derecho aumentarán progresivamente, pese a que los espacios que ocuparon las abogadas eran diferentes de los que ocupan los varones. Como señala Marianne González Le Saux, durante buena parte del siglo XX, las abogadas trabajaban en reparticiones públicas, o en los escalafones más bajos del Poder Judicial, ya que tanto el sueldo como el prestigio de estas actividades era relativamente bajo y, por tanto, menos atractivo para los hombres'. Es decir, las mujeres podían ocupar aquellos espacios que los hombres no querían.

Sin embargo, como señala Olsen, por mucho que el derecho se considere como un ámbito masculino, los rasgos asociados a las mujeres no han sido eliminados del derecho, sino más bien ocultados. En este sentido, el derecho reconoce los rasgos femeninos (lo subjetivo, contextual, irracional) pero tiende a separarlos y marginalizarlos dentro del ámbito del pensamiento y la práctica legal. Así, por ejemplo, sucede con el derecho de familia, en el cual se aceptan estos rasgos femeninos, pero no en otras áreas, como el derecho comercial o el constitucional ${ }^{10}$.

De esta forma, la división sexual-laboral a la que nos hemos referido más arriba se reproducirá también al interior de la profesión legal, reservando espacios del ejercicio profesional más adecuados para las mujeres y otros para los hombres. Esta vinculación entre valores femeninos, que tradicionalmente se consideran de menor jerarquía que los masculinos, y un ámbito de acción específico en donde pueden desplegarse, el derecho de familia (o de menores), produce, entonces, su desvalorización.

11 A partir de lo anterior, el objetivo de este artículo es demostrar cómo opera este proceso de feminización y desvalorización de la posición laboral de la mujer en un espacio específico de la profesión jurídica, como es la Justicia de Menores. Asimismo, nos preguntamos por las consecuencias que puede haber tenido este proceso sobre este espacio particular del sistema judicial, atendiendo a que esta desvalorización está presente hasta hoy.

12 Este artículo analizará el proceso antes descrito entre los años 1928 y 1968. En 1928 se funda el primer tribunal de menores de Chile, encabezado por un varón. En 1968, ya se han creado nueve juzgados de menores a lo largo de todo el país, y todos ellos están dirigidos por mujeres, lo cual nos da pie para hablar de una feminización de la Justicia de Menores.

13 Para abordar nuestra hipótesis, utilizaremos una metodología cuantitativa que nos permita dar cuenta de la progresiva feminización de la Justicia de Menores, y posteriormente, utilizaremos el análisis de discurso para comprobar la desvalorización que afecta a este espacio de justicia hasta la actualidad.

\section{Feminización cuantitativa en la Justicia de Menores}

Desde fines del siglo XIX y, especialmente, en la primera década del siglo XX, surgen voces desde el mundo político y desde la sociedad civil que plantean la urgencia por solucionar el problema de los menores abandonados o que se encontraban en "peligro 
moral". Esto quería decir, aquellos niños y niñas que vivían o trabajaban en las calles, que se dedicaban a la vagancia y que cometían delitos menores. Estos menores eran considerados como los futuros delincuentes del país porque "La mendicidad, la vagancia y el juego son los factores que más fácilmente desvían al niño de la moralidad, y que apoderándose de él lo ponen en la senda del crimen" ${ }^{11}$.

15 Para intentar solucionar este problema, se dictó la primera Ley de Protección de la Infancia Desvalida (4 de septiembre de 1912), que, en teoría, se hacía cargo de los menores abandonados y/o afectados por situaciones de abusos y explotación laboral. Si bien esta ley es un primer intento de parte del Estado por hacerse cargo de los menores en situación de abandono, su aplicación fue muy restringida y no generó mayores cambios, ya que se concentró en la reclusión de niños vagos y delincuentes ${ }^{12}$.

En este contexto, los debates e ideas extranjeras en relación con los derechos del niño comenzaron a difundirse en nuestro país en la década de 1920. En 1924, en la ciudad de Santiago, se realizó el IV Congreso Panamericano del Niño, y al final de este, los participantes aprobaron por unanimidad la "Declaración de Ginebra", adoptada por la Sociedad de las Naciones, que ponía de manifiesto una nueva aproximación hacia la protección debida a los menores. De este modo, paulatinamente, la preocupación por los menores comenzó a tomar fuerza, tanto en organizaciones como la Cruz Roja como entre la sociedad en general ${ }^{13}$.

Esta preocupación por los menores abandonados y “en peligro moral”, obedece a lo que Duncan Kennedy llama el pensamiento legal con orientación social, que comenzó a surgir a comienzos del siglo XX y que se extenderá hasta la década de los 60. Esta concepción del pensamiento legal pone el acento en las condiciones de vida generadas por las transformaciones sociales, las cuales se pueden observar en los efectos de la urbanización, de la industrialización y de la precarización de la vida de las clases populares. El pensamiento legal con orientación social buscaba responder a las necesidades de las sociedades en proceso de modernización, a diferencia del pensamiento legal clásico, de tendencia mucho más individualista ${ }^{14}$. Esta aproximación social al derecho permitirá incorporar miradas más subjetivas y sensibles a las condiciones de vida de las personas, con lo cual se requerirán nuevos procedimientos y nuevos tribunales ${ }^{15}$. En este sentido, la familia, por ejemplo, adquiere importancia para el pensamiento legal con orientación social, ya que tiene funciones y propósitos cruciales para la sociedad, y, por tanto, no es solo una institución privada ${ }^{16}$.

En este contexto de pensamiento legal con orientación social, se dicta la Ley de Protección de Menores no 4.447 (1928), la cual creará la institucionalidad relacionada con la protección de la infancia en nuestro país. Esta norma establece que este es un tipo especial de justicia, por lo que requiere de instituciones específicas encargadas de la protección de los menores, como la Dirección General de Protección de Menores y al primer tribunal de este tipo (ubicado en Santiago).

19 Respecto de los jueces de menores, la ley establece que serán jueces especiales, que deberán tener las cualidades requeridas para el desempeño de las funciones de Juez de Letras de Mayor Cuantía y comprobar conocimientos de psicología. Además, en cada juzgado de menores se crea la plaza de secretario, que ejercerá como "ministro de fe pública, autorizará las providencias, despachos y actos emanados del juez, y custodiará los expedientes y todos los documentos que se presenten al Tribunal" ${ }^{17}$. También debía reemplazar al juez en los casos en que este se ausentara, por lo que debía contar con el título de abogado. 
20 Ahora bien, el primer tribunal creado por la Ley 4.447 quedó encabezado por Samuel Gajardo, el principal impulsor de la Justicia de Menores en nuestro país y secundado por Helia Escudero Guzmán, abogada de la Universidad de Chile, titulada en 1923 con una tesis sobre "La institución de la Cruz Roja". Escudero ingresó al Poder Judicial en enero de 1929 como secretaria del 1er Juzgado de Menores de Santiago y se mantuvo por 28 años en ese mismo cargo, hasta que, en 1957, tras la muerte de Gajardo, fue nombrada jueza de ese mismo tribunal.

21 Por cierto, Helia Escudero no es la primera jueza de nuestro país. Ya desde 1946 podemos encontrar a algunas mujeres encabezando juzgados de menor cuantía, mayoritariamente en provincias, como Corina Mera en Valdivia, Celia Pérez en Quillota, o María Mora en San José de la Mariquina ${ }^{18}$. Sin embargo, lo que llama la atención de la trayectoria profesional de Helia Escudero es su similitud con la de otras juezas de menores.

Es el caso de Fanny Leibovich Guberman, quien se titula de abogada de la Universidad de Chile en 1929 e ingresa al Poder Judicial en octubre de 1934 como secretaria del Primer Juzgado de Menores de Valparaíso. Estuvo 25 años en el mismo cargo hasta que en 1959 asume como jueza de ese tribunal ${ }^{19}$. También es el caso de Eliana Loyola, titulada de la Universidad de Chile en 1936, ingresa al Poder Judicial en 1937, y en 1939 es nombrada secretaria del Segundo Juzgado de Menores de Santiago. 22 años después, en 1961, asume como jueza del recién creado Tercer Juzgado de Menores de Santiago.

De este modo, las tres primeras juezas de menores de nuestro país ejercieron durante más de dos décadas como secretarias de juzgado, antes de llegar al cargo de juezas. Estos datos no nos permiten hacer conclusiones con respecto a los tiempos de ascenso de las mujeres versus los hombres, ya que en este tipo de decisiones influyen no solo aquellos requisitos profesionales relacionados con la carrera dentro del Poder Judicial, sino también, y a veces de manera muy determinante, elementos de tipo personal o familiar, que, por ejemplo, pueden inhibir a algún candidato a postular a algún cargo que implique salir de la ciudad en que él o ella y su familia viven. Sin embargo, nos parece relevante mencionar que estas tres primeras juezas de menores construyeron su carrera durante décadas en esta área específica de la judicatura. Incluso cuando en 1972 fallece Fanny Leibovich siendo presidenta de la Corte de Apelaciones de Valparaíso, el homenaje que le hace la Cámara de Diputados destaca especialmente su labor como jueza de menores, más que como Ministra de Corte:

"Pero su acción que tuvo más hondo sentido humano fue la que realizó, con verdadero afecto y ternura de mujer, como Juez de Menores de Valparaíso, durante muchos años. Ese cargo, uno de los más importantes dentro de la judicatura que defiende a través de la justicia a los más desamparados y débiles de los miembros de la sociedad, requiere de una prudencia, de un alto sentido humano y de una nobleza de alma que sólo personas como Fanny Leibovich podrían desempeñar"20.

Ahora bien, si estas tres trayectorias laborales nos permiten intuir que la Justicia de Menores operó como un espacio de promoción profesional para abogadas en el Poder Judicial, los datos que aporta el Escalafón primario del Poder Judicial lo corroboran.

Una primera mirada al Gráfico 1 nos permite sacar una conclusión general, y es que en el período 1946-1968, la gran mayoría de las abogadas que trabaja en el Poder Judicial lo hace en labores subalternas, como secretarias de juzgado. Una mirada más pausada al gráfico nos muestra que, a partir de 1950 comienza a aumentar el número de juezas de 
juzgados de Letras, y ya en 1954 encontramos a tres mujeres encabezando juzgados del Crimen, número que no cambiará sustancialmente con los años, llegando a 6 en 1968.

Gráfico 1: Juezas y secretarias de juzgado (Chile, 1946-1968)

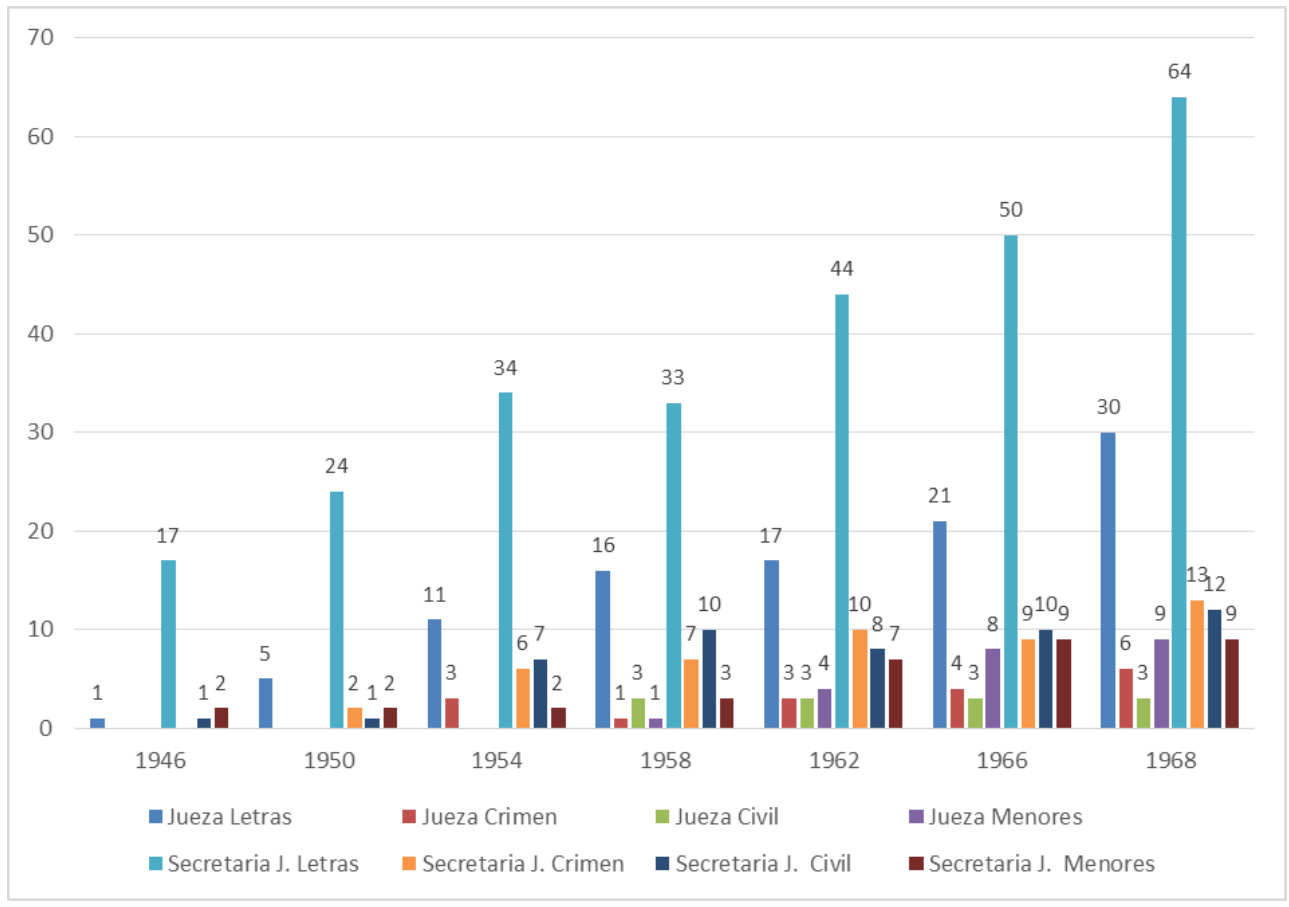

Fuente: Elaboración propia, a partir de los datos del "Escalafón Primario del Poder Judicial", Biblioteca de la Corte Suprema, Santiago. Iniciamos el gráfico en 1946, ya que es el año de nombramiento de la primera jueza en Chile.

Si observamos el caso específico de los juzgados de menores, podremos comprobar que la llegada de las mujeres es evidente y que, a diferencia de lo que ocurre en otros juzgados, se da en un lapso corto de tiempo. En 1957 se nombra a la primera Jueza de Menores en Santiago (Helia Escudero); en 1959 se nombra a la primera Jueza de Menores en Valparaíso (Fanny Leibovich). En 1962 hay cuatro mujeres encabezando juzgados de menores, y seis años después, en 1968, los nueve tribunales de menores están liderados por juezas y secretarias de juzgado.

Sin embargo, para contextualizar estos datos es necesario preguntarse qué ocurre en los otros juzgados del país. Las Tablas 1 y 2 nos muestran la cantidad de juzgados y la cantidad y proporción de juezas en el período 1962-1968. De acuerdo con la Tabla 1, podemos observar que en el año 1962 la mayor proporción de juezas está en los juzgados de menores $(57,1 \%)$, y, luego en los tribunales de menor cuantía, es decir, pertenecientes a las categorías más bajas del escalafón primario $(42 \%, 50 \%, 33,3 \%)$. En los tribunales civiles de mayor cuantía y en la Corte de Apelaciones, no hay presencia de mujeres.

Tabla 1. Proporción de juezas en Chile, año 1962

\begin{tabular}{|l|l|l|l|}
\hline Tipos de Juzgados 1962 & $\begin{array}{l}\mathrm{N}^{\circ} \text { de Juzgados, } \\
\text { Período } 1962\end{array}$ & $\begin{array}{l}\mathrm{N}^{\circ} \text { de Juezas, } \\
\text { Período 1962 }\end{array}$ & Proporción \\
\hline
\end{tabular}




\begin{tabular}{|l|l|l|l|}
\hline Juzgados de Corte de Apelaciones & 10 & 0 & $0 \%$ \\
\hline Juzgados de Menores & 7 & 4 & $57,1 \%$ \\
\hline $\begin{array}{l}\text { Juzgados del Crimen (mayor } \\
\text { cuantía) }\end{array}$ & 11 & 1 & $9 \%$ \\
\hline $\begin{array}{l}\text { Juzgados Civiles (mayor cuantía) } \\
\text { Juzgados (todas } \\
\text { divisiones admin.) }\end{array}$ & 704 & 0 & $0 \%$ \\
\hline $\begin{array}{l}\text { Juzgados de Menor Cuantía (sin } \\
\text { especialidad) }\end{array}$ & 19 & 8 & $7,7 \%$ \\
\hline Juzgados de Menor Cuantía Crimen & 4 & 8 & $42,1 \%$ \\
\hline $\begin{array}{l}\text { Juzgados de Menor Cuantía Civil } \\
\text { Fuente: Escalafón Primario del Poder Judicial, Biblioteca de la Corte Suprema, Santiago. }\end{array}$ & 9 & 2 & $33,3 \%$ \\
\hline
\end{tabular}

En Tabla 2 podemos observar que para 1968 la situación no ha variado mucho, salvo porque las mujeres representan el $100 \%$ de los jueces de menores. En los tribunales de menor cuantía continúan teniendo porcentajes altos (75\%) y relativamente altos (57\%), pero en los juzgados de Mayor Cuantía el alza en la proporción de mujeres con respecto a 1962 es casi anecdótica y siguen ausentes de la Corte de Apelaciones. De este modo, es posible concluir que los tribunales de menores se constituyen en un espacio laboral que se feminiza progresivamente, a partir de fines de la década del 50, y con mayor celeridad durante la década de los 60 .

Tabla 2. Proporción de juezas en Chile, año 1968

\begin{tabular}{|l|l|l|l|}
\hline Tipos de Juzgados 1968 & $\begin{array}{l}\mathbf{N}^{\circ} \text { de Juzgados, } \\
\text { Período 1968 }\end{array}$ & $\begin{array}{l}\mathbf{N}^{\circ} \text { de Juezas, } \\
\text { Período 1968 }\end{array}$ & Proporción \\
\hline $\begin{array}{l}\text { Juzgados de Corte de Apelaciones } \\
\text { Juzgados de Menores }\end{array}$ & 9 & 0 & $0 \%$ \\
\hline $\begin{array}{l}\text { Juzgados del Crimen (mayor } \\
\text { cuantía) }\end{array}$ & 14 & 9 & $100 \%$ \\
\hline $\begin{array}{l}\text { Juzgados Civiles (mayor cuantía) } \\
\text { Letras (todas }\end{array}$ & 9 & 2 & $14,2 \%$ \\
\hline $\begin{array}{l}\text { Juzgados de } \\
\text { divisiones admin.) }\end{array}$ & 106 & 0 & $0 \%$ \\
\hline $\begin{array}{l}\text { Juzgados de Menor Cuantía (sin } \\
\text { especialidad) }\end{array}$ & 21 & 12 & $16 \%$ \\
\hline
\end{tabular}




\begin{tabular}{|l|l|l|l|}
\hline Juzgados de Menor Cuantía Crimen & 4 & 3 & $75 \%$ \\
\hline Juzgados de Menor Cuantía Civil & 9 & 2 & $22 \%$ \\
\hline Fuente: Escalafón Primario del Poder Judicial, Biblioteca de la Corte Suprema, Santiago. \\
\hline
\end{tabular}
nuevos tribunales de menores en Santiago, por lo que se abrió concurso para proveerlos de jueces. A estos concursos se presenta un conjunto de candidatos, de entre los cuales la Corte de Apelaciones elige dos. A ellos se suma lo que se denomina "juez por derecho propio", que es el funcionario más antiguo en la categoría, conformándose así la terna.

De acuerdo con la Tabla 3, la mayoría de los candidatos que se presentan a los concursos para los nuevos tribunales de menores son mujeres, salvo en el caso del $4^{\circ}$ juzgado, en el que hay paridad.

\begin{tabular}{|c|c|c|}
\hline Concurso & Candidatos & Elegido \\
\hline 3er Juzgado de Menores, marzo 1961 & $\begin{array}{l}5 \text { mujeres } \\
2 \text { hombres }\end{array}$ & Eliana Loyola Illanes \\
\hline $4^{\circ}$ Juzgado de Menores, abril 1961 & $\begin{array}{l}4 \text { mujeres } \\
4 \text { hombres }\end{array}$ & Hernán Cereceda Bravo \\
\hline $5^{\circ}$ Juzgado de Menores, mayo 1961 & $\begin{array}{l}6 \text { mujeres } \\
3 \text { hombres }\end{array}$ & Marta Ossa Reygadas \\
\hline
\end{tabular}

Ahora bien, para que esta información sea una evidencia de la feminización que proponemos, debemos analizar qué ocurre en los otros juzgados en la misma época.

Tabla 4. Concurso para diferentes tribunales, 1959-1961

\begin{tabular}{|l|l|}
\hline Concurso & Candidatos \\
\hline $2^{\circ}$ J. Mayor Cuantía del Crimen de Stgo. Julio 1959. & 1 mujer / 4 hombres \\
\hline Juzgado de Letras de Caupolicán. Julio 1959. & 1 mujer / 2 hombres \\
\hline
\end{tabular}




\begin{tabular}{|l|l|}
\hline $\begin{array}{l}2^{\circ} \text { J. de Menor Cuantía del Crimen de Santiago. Agosto } \\
1959 .\end{array}$ & 4 mujeres / 4 hombres \\
\hline Juzgado de Letras de Rancagua. Agosto 1959. & 4 hombres \\
\hline Juzgado de Letras de Talagante. Enero 1960 & 2 mujeres / 8 hombres \\
\hline $2^{\circ}$ J. de Menor Cuantía Civil de Stgo. Enero 1960 & 5 mujeres / 1 hombre \\
\hline 3er J. de Mayor Cuantía del Crimen de Stgo. Marzo 1960 & 2 mujeres / 6 hombres \\
\hline Juez de Letras de San Fernando. Mayo 1961 & 1 mujer / 6 hombres \\
\hline Juez de Letras de Rancagua. Junio 1961. & 4 hombres \\
\hline $\begin{array}{l}\text { Fuente: Elaboración propia, a partir de “Actas: acuerdos del tribunal: Junta de Servicios Judiciales”, } \\
\text { Biblioteca de la Corte Suprema, Santiago, Chile, Colección Corte de Apelaciones de Santiago, vol. 23, } \\
\text { foja s.n. }\end{array}$
\end{tabular}

En la Tabla 4 podemos observar que en todos los concursos para juzgados que no son de menores hay considerablemente menos candidatas mujeres que hombres, y en algunos no hay candidatas. La única excepción es el concurso para el $2^{\circ}$ Juzgado de Menor Cuantía Civil de Santiago (enero 1960), que tiene 5 candidatas y 1 candidato, y, sin embargo, la terna quedó compuesta por dos hombres y una mujer, al agregarse el juez por derecho propio, quien finalmente obtuvo el cargo.

En este sentido, los concursos para el cargo de juez de los años 59, 60 y 61 nos muestran claramente que en los tribunales de menores hay una mayor presencia de mujeres, tanto entre las postulantes al cargo como entre quienes obtienen finalmente el cargo. No ocurre lo mismo con los concursos para otros juzgados, en esos mismos años, ya que en ellos es posible observar un claro predominio de los candidatos varones. Creemos entonces que ya a fines de la década de los 50 está bastante claro que la Justicia de Menores está viviendo un proceso de feminización.

Y si miramos el panorama actual, la situación no es muy diferente. Según datos de la Secretaría Técnica de Igualdad de género y no discriminación del Poder Judicial, la distribución de jueces por unidad laboral y género es la siguiente:

Tabla 5. Jueces y juezas en el poder judicial (distribución por sexo), Chile, 2019

\begin{tabular}{|l|l|l|l|}
\hline Unidad laboral & Hombres & Mujeres & Brecha \\
\hline Juzgado civil & $29,8 \%$ & $70,2 \%$ & $40,4 \%$ \\
\hline $\begin{array}{l}\text { Juzgado de cobranza laboral y } \\
\text { previsional }\end{array}$ & $26,7 \%$ & $73,3 \%$ & $46,7 \%$ \\
\hline Juzgado de familia & $21,7 \%$ & $78,3 \%$ & $56,6 \%$ \\
\hline Juzgado de garantía & $48,6 \%$ & $51,4 \%$ & $2,8 \%$ \\
\hline
\end{tabular}




\begin{tabular}{|l|l|l|l|}
\hline Juzgado de letras & $56,0 \%$ & $44,0 \%$ & $-12,1 \%$ \\
\hline Juzgado de letras del trabajo & $43,3 \%$ & $56,7 \%$ & $13,4 \%$ \\
\hline $\begin{array}{l}\text { Tribunal de juicio oral en lo } \\
\text { penal }\end{array}$ & $42,5 \%$ & $57,5 \%$ & $15,1 \%$ \\
\hline Total nacional & $\mathbf{3 9 , 9 \%}$ & $\mathbf{6 0 , 1 \%}$ & $\mathbf{2 0 , 2 \%}$ \\
\hline $\begin{array}{l}\text { Fuente: Poder Judicial, Secretaría Técnica Igualdad de género y no discriminación, "Mujeres y hombres en números } \\
\text { en el Poder Judicial", Portal Secretaría de Genero del Poder Judicial. Disponible en: http://secretariadegenero.pjud.cl/ } \\
\text { index.php/mujeres-y-hombres-en-numeros-en-el-poder-judicial [Fecha de consulta: 16 de agosto de 2020] }\end{array}$ \\
\hline
\end{tabular}

La tabla muestra cómo las mujeres, que corresponden al $60,1 \%$ de los jueces a nivel nacional, están sobre representadas en los tribunales de familia (antiguos tribunales de menores), llegando al $78,3 \%$. Esta tabla nos permite concluir que la feminización que hemos registrado a partir de los años 50 se proyecta hasta la actualidad, afectando según nuestra hipótesis - a este ámbito de la justicia.

\section{Subjetividad y afectos en los tribunales de menores}

La feminización que planteamos no sólo se evidencia por el número de mujeres que trabajan en la Justicia de Menores, sino también por la asociación de este espacio de justicia con un conjunto de características tradicionalmente consideradas como femeninas. Estas características se pueden observar, por ejemplo, en las competencias y/o habilidades que debían tener los funcionarios, y en particular los jueces, que se dedicaban a este ámbito judicial.

La primera referencia que encontramos a las competencias especiales que debían tener los jueces de menores aparece en los debates parlamentarios de la Ley 4.447 de 1928, en boca del secretario de la Comisión Mixta de senadores y diputados que debía informar sobre el proyecto de ley de infancia desvalida. Allí, defendiendo la necesidad de que existieran tribunales especiales para los menores de 20 años, la comisión destaca que estos jóvenes no quedarían al margen de la autoridad, sino que "quedan sometidos al Juez de Menores, a este funcionario que, además de ser un hombre de derecho y con conocimiento de psicología, va a desempeñar sus funciones en forma, puede decirse, paternal"22. Incluso se considera que los jueces de menores debían ser padres, "porque un juez que no los tiene no está capacitado para conocer el alma de los niños" 23 . Llama la atención esta referencia a la paternidad, no en tanto jefe de familia o autoridad, sino más bien vinculada al cuidado y la protección de los menores. Podemos postular así que la concepción de padre autoritario está siendo reemplaza, o, al menos coexiste, con una idea de paternidad más cercana al rol de la madre.

Finalmente, la Ley 4.447 en su artículo 14, establece que "Para poder ser Juez de Menores será necesario tener las calidades requeridas para el desempeño de las funciones de Juez de Letras de Mayor Cuantía de departamento, y comprobar conocimientos de psicología, en la forma que determine el Reglamento" ${ }^{24}$.

Los conocimientos de psicología se transformaron en un requisito clave en este nuevo derecho de menores, que se alejaba de las nociones más tradicionales sobre la criminalidad, haciendo eco del positivismo científico, de las teorías patológicas y de las 
teorías ambientalistas ${ }^{25}$. En este contexto, era indispensable comprender al menor delincuente como un producto de factores ambientales, sociales y hereditarios, y buscar formas de rehabilitación antes que solo aplicar una pena específica, para lo cual la psicología aparecía como una disciplina fundamental.

De esta manera, las referencias al conocimiento de psicología que aparecen tanto en la ley como en los debates parlamentarios, así como las referencias a una cierta actitud paternal del juez hacia el menor, refuerzan la condición "especial" de estos tribunales en los cuales se hacía necesaria, como señaló un diputado en 1928, "una comprensión del alma infantil".

La Ley 4.447, promulgada en 1928, supone una transformación profunda de la aproximación legal hacia los menores. Según señala Jorge Rojas, "el principio que estuvo detrás de esta legislación fue que a los niños no se les podía aplicar la misma legislación penal (ni siquiera reducida, como se hacía hasta entonces) que a los adultos" ${ }^{26}$. Esta forma de entender el derecho aplicado a los menores suponía que las medidas punitivas no solucionaban el problema dado que este tenía causas sociales, fisiológicas y culturales, y a eso había que apuntar. De ahí la importancia de la reeducación de los menores inadaptados o que hubiesen cometido delitos.

Un punto central de esta nueva aproximación jurídica hacia los menores lo constituyó la figura del discernimiento ${ }^{27}$, que, según Rojas, "se entendió en el sentido de la "utilidad social" o "readaptabilidad social", y no como la capacidad racional para distinguir las consecuencias de sus actos" ${ }^{28}$. De este modo, el concepto de discernimiento fue susceptible de interpretación de acuerdo con el criterio de los jueces, abriendo así espacio a la subjetividad de cada magistrado.

Ahora bien, este espacio para la interpretación sobre el discernimiento no estuvo exento de conflictos. Según Gajardo, las tensiones que se producen entre el Código Civil y los tribunales de menores se deben a la aplicación de una misma regla jurídica a casos antagónicos, "lo que resulta una inepcia que deberá resolverse a través de la justicia racional y sentimentalista, lo que supondrá aplicar medidas diversas para situaciones diversas"29. De este modo, Gajardo reivindica más libertad de interpretación de las normas para el juez de menores, y especialmente, releva la importancia de los afectos y sentimientos que deben estar presentes en estos tribunales.

El mismo juez Gajardo profundiza en este asunto cuando establece que "el Juez de Menores no debe ser un jurista diestro en cubileteos legales. Debe ser un hombre humano, un verdadero maestro, un psicólogo capaz de ponerse al nivel del alma infantil y comprender los valores efectivos de la personalidad del niño"30.

Consideramos que el papel preponderante que adquiere lo subjetivo y lo afectivo, ejemplificado en las referencias a la paternidad, a la comprensión y al cuidado, será un elemento fundamental para el proceso de desvalorización de la Justicia de Menores. Esto se debe a que, tradicionalmente, se consideraba que la imparcialidad y la racionalidad eran valores prioritarios de la profesión legal, y en particular de la judicatura, por lo que no debía dejarse espacio a la emoción y a la subjetividad como elementos a considerar en las decisiones judiciales.

Como señala María Eugenia Albornoz, las ideas racionales provenientes de la Ilustración y que modelan las instituciones y sistemas normativos modernos, establecen que: 
"el lugar de elaboración del juicio del juez deja de ser su sentimiento subjetivo y personal (que circula por su cuerpo y su persona entre mente, espíritu, alma, corazón, esto es, en toda su singular, única e irrepetible subjetividad), para trasladarse en cambio a su raciocinio, el cual debiera, para ser correcto eficiente y útil, liberarse de su parte personal y subjetiva, que está estrechamente ligada al sentimiento" ${ }^{31}$. apegadas a códigos y leyes, que establecen los "hechos jurídicos", de las cuales se debe eliminar cualquier rastro de subjetividad, toda vez que esa decisión puede ser discutida o incluso revocada por instancias superiores de justicia ${ }^{32}$. Esta tensión entre la sentencia absolutamente racional y aquella en donde perviven aspectos subjetivos será permanente en la Justicia de Menores, tal como relata Samuel Gajardo en sus memorias:

"Obrar con discernimiento significaba comprender la ilicitud y naturaleza del acto y sus consecuencias. Si yo hubiera aplicado este criterio gramatical y psicológico a los muchachos menores de veinte años que habían cometido un delito, ninguno se habría escapado, pues todos obran con discernimiento. Todos habrían tenido que ser remitidos a la cárcel para ser juzgados por el Juez del Crimen, aun cuando hubieran cometido un delito sin importancia. Ante esta alternativa de aplicar textualmente la ley y ser un juez malo o aplicarla con sentido humano y ser un buen juez, opté sin vacilar por esto último y fue así como declaré siempre que un menor obró sin discernimiento, como fórmula para poderlo proteger, sustrayéndolo a la cárcel”33.

Asimismo, y referido a los sentimientos que debían estar presentes en los tribunales de menores, Gajardo señalaba que, para proteger a un niño de manera adecuada, "debe entregársele afecto al igual que lo hace una familia tradicional. En caso de no contar con esta, los funcionarios tienen la obligación de estar comprometidos con su labor para suplir las necesidades afectivas del niño"34.

En este contexto, podemos ver que, desde sus inicios, el juez de menores debía tener competencias ligadas a lo afectivo más que a lo racional, o, al menos debía poseer ambas en iguales condiciones. El hecho de que se le pida a los funcionarios de los tribunales de menores, y en particular al juez, una actitud paternal, afectuosa, comprensiva con el alma del niño nos permite señalar que, aunque los primeros jueces de menores fueron hombres, las características que supuestamente se requerían para realizar esta labor produjeron su identificación con lo femenino. Valores como lo subjetivo, lo irracional (o emocional) y lo particular, vinculados a lo femenino y poco valorados por las concepciones tradicionales del derecho, están muy presentes en la Justicia de Menores, estableciéndose así una marginalización de este ámbito ${ }^{35}$.

\section{Reformas a los tribunales de menores en los años 1950 y 1960: el protagonismo de las mujeres}

Desde la ley de 1928 hasta aproximadamente 1960, no hubo grandes transformaciones en el sistema de protección de menores, salvo la creación del Primer Juzgado de

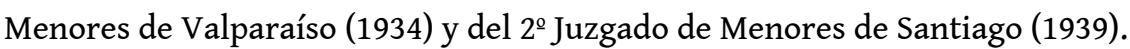

La primera reforma importante se produjo en 1961, con la Ley 14.550, que crea cuatro nuevos juzgados de menores en Santiago ( $3^{\circ}, 4^{\circ}$ y $5^{\circ}$ y Juzgado de San Miguel) y modifica algunos aspectos de la Ley 4.447. Producto de esta reforma, en 1962 se contabilizaban siete tribunales de menores distribuidos en Santiago y Valparaíso ${ }^{36}$, y de 
acuerdo con el gráfico $\mathrm{n}^{\circ} 1$, cuatro de estos tribunales estaban encabezados por juezas, $\mathrm{y}$ la totalidad de ellos cuenta con secretarias de juzgado.

Además de crear nuevos tribunales, la Ley 14.550 establece que los juzgados de menores que existen en el país y los que la misma ley crea, pasarán a llamarse Juzgados de Letras de Menores, y, al igual que establecía la Ley 4.447, "se regirán por las disposiciones relativas a los Juzgados de Letras de Mayor Cuantía establecidas en el Código Orgánico de Tribunales" ${ }^{\prime 3}$. Hasta ese momento, eran tribunales especiales dentro del Poder Judicial.

Sin embargo, en el artículo 16 de la misma ley, se establece que:

"los Jueces y Secretarios de los Juzgados de Letras de Menores no podrán ser designados para cargos de categorías superiores del Escalafón Primario, sino después de cinco años de haber servido como tales en la respectiva categoría de dicho Escalafón que les asigna la presente ley"38.

Llama la atención esta limitación que se introduce a jueces y secretarios de juzgados de menores, toda vez que solo rige para ellos - a estas alturas, ellas - y no para los otros juzgados de Letras de Mayor Cuantía, según cuyas disposiciones debían regirse los tribunales de menores.

Si cruzamos este dato con los de los concursos para proveer de jueces a los nuevos tribunales de menores (ver Tabla 3), en donde la mayoría de las candidatas son mujeres, podríamos pensar que esta limitación introducida por la Ley 14.550 hizo que estos cargos fueran menos atractivos para el desarrollo profesional porque limitaban las posibilidades de ascenso, de lo que podría resultar un menor interés de los varones por postular a ellos.

57 Ahora bien, la ley no indica el objetivo de este artículo, aunque en la discusión parlamentaria se hace una breve referencia a este, señalando que sería para "procurar cierta permanencia de estos jueces especializados" 39 . Es interesante constatar que a comienzos de la década de los 60 , los jueces y secretarios de los tribunales de menores se siguen considerando funcionarios especializados que deben poseer conocimientos $\mathrm{y}$ competencias específicas.

La Ley 14.550 también exige que los jueces y secretarios de juzgados de menores tengan y comprueben conocimientos de psicología, tal como lo hacía la ley anterior, y en la discusión parlamentaria vuelve a aparecer la necesidad de que estos funcionarios tengan una aproximación más afectiva hacia los menores:

"No cabe duda que para resolver la situación de jóvenes que han debido ser llevados ante los Tribunales por actos antisociales o delictivos, se requiere que el magistrado posea los conocimientos para llegar hasta su psiquis, hasta su alma, en la forma más profunda. También es fundamental este conocimiento para resolver, con un criterio humano más que legalista, las diversas situaciones anómalas que se someten a conocimiento de los Tribunales y buscar la solución más justa para estos problemas sociales" 40 .

Otro elemento que cabe destacar en este análisis, aunque no está directamente relacionado con la figura del juez de menores, es lo que atañe a las visitadoras sociales, profesión que tuvo un auge a partir de las primeras décadas del siglo $\mathrm{XX}^{41}$. Como señalamos más arriba, la Ley 4.447 no solo creó el Primer Juzgado de Menores del país, sino que también creó las Casas de Menores, que se fundarían asociadas a estos tribunales, y que contarían con cuatro visitadoras sociales encargadas de informar de la situación de los menores al director de la Casa de Menores y al juez. 
60 En el debate de la Ley 14.550, la figura de los asistentes sociales ha adquirido más importancia, y, de hecho, se habla de ellos como el eslabón entre el menor en su entorno (familiar o en la casa de menores) y el juez. Los informes de los asistentes sociales pasan a ser cruciales en las decisiones del juez de menores. Así, el diputado radical Flores Castelli, miembro de la Comisión de Constitución, Legislación y Justicia, al presentar la ley ante la Cámara de Diputados señala que las funciones de "las asistentes sociales son de extraordinaria importancia. Sus informes tendrán un valor equivalente a los que emiten Carabineros o Agentes de Investigaciones" ${ }^{42}$.

61 Esta presencia femenina en la figura de la asistente social es permanente en el tiempo, así como la valoración que se hace de su trabajo. En el debate de la Ley 16.520 (1965), que crea el Consejo Nacional de Menores, el Ministro de Justicia, Pedro Jesús Rodríguez, señalaba al respecto: "Esas profesionales serán valiosos elementos de colaboración para los magistrados. Sin duda, la función de las asistencias sociales es de carácter especial: prestan al juez un servicio que solo ellas están en condiciones de proporcionar" ${ }^{43}$. Cabe preguntarse si ese "solo ellas" es en tanto asistentes sociales o en tanto mujeres, poseedoras de un conjunto de características que las harían especialmente aptas para comprender a los menores.

62 En cuanto a esto, Marianne González Le Saux señala que, en el contexto del Servicio de Asistencia Judicial (1932-1981), la relación laboral entre abogados y asistentes sociales supuso un reparto de tareas sexualizado y jerarquizado. Las visitadoras sociales cumplían la función de mediadoras entre los abogados y las personas mayoritariamente de escasos recursos- que recurrían a la asistencia judicial. Las visitadoras también le ahorraron tiempo precioso a los abogados cumpliendo las funciones de 'traductoras': llevar a cabo la labor feminizada de escuchar los problemas de los pobres, de modo que los abogados podrían tener sólo la versión abreviada y 'útil' de los hechos inmediatamente relevantes al caso judicial ${ }^{44}$. De este modo, la figura de la asistente social refuerza esta visión sexualizada y jerarquizada del derecho ${ }^{45}$.

63 El rol preponderante que cumplen las asistentes sociales en la justicia de menores, en comparación con otros ámbitos de la administración judicial, evidencia que la presencia femenina se vuelve hegemónica en este espacio profesional, especialmente si consideramos que hacia fines de la década de los 60, los nueve tribunales de menores a lo largo del país están encabezados por juezas y secundados por secretarias.

¿Esta presencia mayoritaria de mujeres en los tribunales de menores significa necesariamente una desvalorización de este ámbito de la justicia? Creemos que sí. Como señala Rose-Marie Lagrave, refiriéndose a la dicotomía género-trabajo:

las posiciones dominantes son ocupadas siempre por varones; las desvalorizadas por mujeres. Por ejemplo, un oficio feminizado ya no se masculiniza. Cuando las mujeres progresan en una profesión, los hombres desertan o lo han hecho ya antes. No se trata de una situación de rivalidad, ni de competencia justa sino de una defección silenciosa ${ }^{46}$.

65 De este modo, no vamos a encontrar, a lo largo del período estudiado, un discurso explícito que desvalorice el derecho de menores o los tribunales y funcionarios encargados de ejercerlo. Sin embargo, sí encontramos la defección silenciosa de la que habla Lagrave, no solo en el alto porcentaje de mujeres que trabajan en los tribunales de menores sino también en la escasa relevancia que espacios profesionales vitales para el mundo del derecho, como el Colegio de Abogados, le otorgan a este tema. Solo como ejemplo, la Revista de Derecho y Jurisprudencia, vinculada al Colegio de Abogados de 
Chile, publicó apenas 7 artículos sobre derecho de menores en el período 1928 - 1968, lo cual corresponde al $1,7 \%$ de sus artículos.

Siguiendo esta misma línea, los estudios de Marianne González Le Saux sobre el desarrollo de la profesión legal durante el siglo XX, explican muy claramente las dificultades que tuvieron las abogadas para insertarse en este ámbito profesional, y cómo los varones intentaron defender este espacio, considerado masculino por excelencia. Así, por ejemplo, González recoge una entrevista que Felicitas Klimpel hizo a Arturo Alessandri Rodríguez en 1940, cuando era presidente del Colegio de Abogados, en la que señala que la profesión legal no era apropiada para las mujeres, porque se trataba de una profesión que implicaba conflicto y lucha, lo cual no se ajustaba a la naturaleza femenina ${ }^{47}$. Sin decirlo explícitamente, Alessandri deja entrever que las mujeres no tendrían las capacidades intelectuales suficientes para ejercer la profesión legal, y que se espera que ellas ejerzan profesiones en donde puedan poner en práctica dicha naturaleza, ejemplificada en el afecto, la ternura y el cuidado de otros.

Asimismo, otras opiniones en el mundo del derecho, sin afirmar que la profesión legal no es adecuada para las mujeres, refuerzan la idea de que existen espacios diferenciados para abogadas y abogados dentro de la profesión legal. Por ejemplo, Delia Silva, en su tesis titulada La Mujer Abogada, señala que hay actividades apropiadas para las mujeres, entre las que sitúa a la justicia de menores, precisamente porque para su ejercicio se necesitarían habilidades como la comprensión, el orden y la capacidad de organización, más que fuerza, dureza y rigor ${ }^{48}$.

En suma, desde mediados del siglo XX, las abogadas tuvieron que realizar una dura lucha por validarse como profesionales en el ámbito del derecho, frente a las resistencias de los varones que veían con temor cómo aumentaba el número de mujeres que ingresaba a la profesión, aunque eso significara ocupar posiciones más bajas, peor remuneradas y menos valoradas ${ }^{49}$. La tensión entre el saber profesional y la "naturaleza femenina", que articula la problemática del trabajo femenino, finalmente se resuelve en un proceso de desjerarquización de algunas áreas de la profesión legal en las cuales lo emocional, lo subjetivo y lo particular - valores considerados como femeninos - están presentes. En este sentido, la feminización de la Justicia de Menores no implicó un cuestionamiento a la lógica masculina presente en las concepciones tradicionales del derecho, sino más bien se tradujo en su traslado a los márgenes y en la pérdida de valor de este ámbito profesional, lo cual se ha proyectado hasta la actualidad.

\section{La persistencia de estereotipos de género y valoraciones sociales negativas sobre la Justicia de Menores/Derecho de familia en el s. XXI50}

El estereotipo de género que establece que la mujer se desempeña mejor en la Justicia de Menores, producto de una supuesta naturaleza femenina, persiste hasta hoy, como señala el estudio sobre "Igualdad de género y no discriminación. Proyecto de Estudio Diagnóstico de la perspectiva de Igualdad de Género en el Poder Judicial Chileno", realizado por la Dirección de Estudios de la Corte Suprema en 2015-2016. El estudio, que encuestó al 36\% de los funcionarios y funcionarias del Poder Judicial, arrojó resultados sorprendentes, que sintetizamos en la siguiente tabla ${ }^{51}$. 
70 Ante la pregunta por quién se desempeña mejor en las siguientes actividades en materia judicial, las respuestas fueron:

Tabla 6. Percepción del desempeño por género en distintos juzgados

\begin{tabular}{|l|l|l|}
\hline Materia & Desempeño similar & Desempeño diferente \\
\hline Civil & $78 \%$ & $5 \%$ \\
\hline Penal & $80 \%$ & $6 \%$ \\
\hline Laboral & $78 \%$ & $5 \%$ \\
\hline Familia & $67 \%$ & $14,1 \%$ \\
\hline
\end{tabular}

FUente: “Igualdad de género y no discriminación. PROYeCto de estudio diagnóstico de La PERSPeCtiva de IgUALDAD DE GÉNERO EN EL PODER JUDICIAL CHILENO", P. 52-53.

71 De esta tabla llama la atención que existe una mayoría de encuestados (78\% promedio) que considera que hombres y mujeres tienen un desempeño similar en las áreas civil, penal y laboral. Sin embargo, este porcentaje desciende a $67 \%$ cuando se refieren al área de familia. El $14 \%$ de los encuestados que fija una posición de género sobre el desempeño en esta área se desglosa en un $12,6 \%$ que cree que las mujeres se desempeñan mejor, frente a un $1,5 \%$ que considera que los varones se desempeñan mejor.

Por lo tanto, podemos concluir que el área de familia en la judicatura es un ámbito que sigue manteniendo fuertes estereotipos de género, que se reflejan también en la distribución de los jueces por jurisdicción, ya que el 78\% de los tribunales de familia están encabezados por mujeres. Al respecto, el informe señala que esta sobrerepresentación de las mujeres en el área de familia, "se justificaría [...], no por un simple acto de elección o preferencia, sino por una supuesta mayor idoneidad de la mujer para las cuestiones familiares, respondiendo a un estereotipo de género en la aplicación del derecho al no existir datos objetivos que lo avalen" ${ }^{52}$.

Con respecto a la desvalorización de esta área, podemos observar que ésta funciona tanto de forma implícita, por ejemplo, en la implementación de la reforma a los tribunales de familia, como de forma explícita, a través de la valoración social negativa que diferentes actores de la profesión manifiestan con respecto al derecho de familia.

Para analizar lo que hemos llamado desvalorización implícita, podemos atender a los esfuerzos realizados por el Estado en relación con el área de familia. María José Azócar aporta datos interesantes al comparar la reforma procesal penal, implementada en el año 2000, con la reforma de familia, que se realiza en 2005. En primer lugar, encontramos una gran diferencia en el presupuesto dedicado a una y otra, ya que en la reforma de familia se invirtió apenas el $20 \%$ de lo gastado en la reforma procesal penal, pese a que ambas reformas tenían aplicación a nivel nacional ${ }^{53}$.

Siguiendo en esta línea, en 2006, un equipo de abogados de la Facultad de Derecho de la Universidad Diego Portales, encabezado por Lidia Casas, publicó una investigación sobre el funcionamiento de los nuevos tribunales de familia, detectando diversos 
problemas, "tanto en el diseño e implementación del sistema como en un conjunto de prácticas que se han ido consolidando entre los diversos actores, lo que, como veremos, pone en entredicho el cumplimiento de las promesas realizadas por el Estado" ${ }^{54}$.

Algunas de las deficiencias que arrojaron los resultados de esta investigación tienen que ver con el equipo técnico que diseñó la reforma, compuesto por 7 personas y sin profesionales de apoyo en las regiones. A este equipo le tocó definir las capacitaciones necesarias para los nuevos jueces y funcionarios, elegir el diseño de los nuevos programas computacionales, difundir la reforma en el país, así como comprar, arrendar y/o remodelar las nuevas instalaciones. A todo esto, se suma la necesaria coordinación que debían hacer con el Poder Judicial. Según los autores del estudio:

"en el caso de la reforma procesal penal, junto con el equipo de coordinación del Ministerio de Justicia, la Defensoría Penal Pública y el Ministerio Público contaban con equipos internos que trabajaron en el proceso de implementación. Además de ello se instaló una Comisión de Coordinación Institucional en la que trabajaban todas las instituciones del sistema para coordinar el proceso de puesta en marcha" ${ }^{5}$.

Ahora bien, la valoración social negativa que manifiestan algunos actores involucrados tanto en la reforma procesal penal como en la de familia, nos permite también demostrar la desvalorización que afecta a esta última área. Según el estudio de María José Azócar, que entrevistó a abogados varones y mujeres que participaron en ambos procesos de reforma, los profesionales relacionados con la reforma procesal penal, todos varones, "movilizaron la imagen de ser profesores de derecho penal. Es decir, de estar vinculados a 'una de las áreas más sofisticadas de la profesión' y de una 'compleja jurisprudencia"' ${ }^{56}$. Por su parte, las abogadas vinculadas a la reforma de familia, todas mujeres, consideraban que:

la decisión de especializarse en el área de familia tenía que ver con una competencia "natural" que radicaba en su sensibilidad "especial" como mujeres; lo que se traducía en su disposición por priorizar acuerdos por sobre la confrontación y a transar compensaciones económicas por las compensaciones emocionales de su trabajo $^{57}$.

78 De esta forma, los mismos protagonistas de las reformas muestran percepciones diferentes respecto de las competencias requeridas para el ejercicio profesional, de acuerdo a las diferentes áreas en las que se desempeñan. Así, el derecho penal sería un área legalista, intelectualmente desafiante y compleja, mientras el derecho de familia sería un área en la cual primaría el diálogo, la mediación y la no confrontación, generándose entonces una jerarquización al interior de la profesión, lo cual redundaría en el mayor o menos prestigio social y profesional de cada una de estas áreas.

79 En este sentido, un estudio de Claudio Fuentes señala que en el área de familia existe un "componente emocional y de una perspectiva interdisciplinaria que contribuirían a la menor preeminencia del debate jurídico, lo que provocaría que la justicia de familia fuese finalmente percibida como más cercana al trabajo social que al derecho. Sería de ahî de donde surge el bajo prestigio del área"58.

80 Según Claudio Fuentes, esta minusvaloración del derecho de familia se debe a que, en los conflictos de esta naturaleza, tiende a primar "la dimensión emocional e interdisciplinaria", por sobre el componente legal ${ }^{59}$. Sin embargo, es factible preguntarse si la emoción, los afectos y la subjetividad son componentes exclusivos del derecho de familia, o bien, también están presentes en otros ámbitos de la profesión legal. Según un estudio de María José Azócar sobre la experticia judicial en los 
tribunales de familia, "el manejo de las emociones está presente en toda profesión, incluida la judicial" ${ }^{60}$. El problema entonces no sería la presencia de la emoción sino más bien cómo la misma profesión valora estas emociones, dado que el reconocimiento de estas no es neutro, sino, como señala Azócar, se sostiene en parámetros androcéntricos, que definen cuáles son las emociones deseables y cuáles no ${ }^{61}$.

De este modo, incluso aceptando la premisa de que las emociones están presentes en todos los ámbitos de la profesión legal, lo que produce la desvalorización del área de familia sería su vinculación con características o emociones consideradas como parte de la supuesta naturaleza femenina, reproduciendo así un estereotipo de género que, como vimos persiste hasta hoy.

\section{Conclusiones}

En el presente trabajo hemos intentado demostrar que, en Chile, los tribunales de menores (hoy tribunales de familia) vivieron un proceso de feminización, desde su creación en 1928 y hasta la actualidad.

Postulamos que la Justicia de Menores operó como un espacio particularmente adecuado para el ejercicio profesional de las abogadas que ingresaban al Poder Judicial, al estar relacionado con una actividad - el cuidado de niños - que las mujeres realizaban tradicionalmente en el espacio doméstico, y en la cual eran especialmente eficientes gracias a su naturaleza femenina. De esta forma, sería esa misma naturaleza la que las haría aptas para desplegar en la esfera pública lo que ya hacían en la esfera doméstica.

Hemos podido comprobar cómo, entre 1928 y 1968, los juzgados de menores de nuestro país ven aumentar el número de mujeres en ellos, tanto en el cargo de juezas como en el de secretarias de juzgado. De la misma forma, la labor de las asistentes sociales también cobra relevancia en estos juzgados, haciendo entonces que la figura de la mujer tenga una presencia muy destacada en la Justicia de Menores.

Postulamos también la importancia de los afectos y emociones en el contexto específico de la Justicia de Menores. En palabras de Samuel Gajardo, comprender el alma del niño es el trabajo esencial del juez de menores, para poder decidir de mejor forma, el destino de ese niño. Y Gajardo tenía razón. Desde la Declaración de Ginebra sobre los Derechos del niño (1924), la protección de los menores, tanto en términos materiales como espirituales, ha sido el centro de la vasta literatura sobre el tema.

86 Ahora bien, nuestra hipótesis postula que la feminización no es sólo cuantitativa sino también -y, muy especialmente- cualitativa, en la medida que la Justicia de Menores se asocia con una serie de características y/o competencias que están más vinculadas al manejo de la emoción y de los afectos que al conflicto legal. De este modo, la dicotomía emoción/razón, que estructura los roles de género tradicionales, opera también en un ámbito profesional específico, desvalorizando un área de dicha profesión debido a su vinculación con lo femenino.

87 Así, las nociones sexualizadas y jerarquizadas del derecho, que lo entienden como racional, objetivo y universal consideran que lo irracional, subjetivo y particular es femenino y, en consecuencia, de menos valor. Por lo tanto, la feminización cuantitativa que postulamos para la Justicia de Menores no supuso la subversión de las lógicas de 
dominación patriarcal en el derecho, sino, más bien, contribuyó a su marginalización y desvalorización.

\section{Fuentes} 2020] Santiago, 1928-1968. Chile, Volumen 23, foja s.n.

Actas Primer Congreso Nacional de Protección de la Infancia, Imprenta Barcelona, Santiago de Chile, 1913. Disponible en: http://www.memoriachilena.gob.cl/602/w3article-57793.html [Fecha de consulta: 25 de mayo de 2020]

Congreso Nacional, Diario de Sesiones del Senado: 23 de noviembre de 1927, Biblioteca del Congreso Nacional, Valparaíso, 1927.

Diputado Guillermo Azócar, “Intervención”, en: Congreso Nacional, Diario de Sesiones del Senado: 11 de junio de 1928, Biblioteca del Congreso Nacional, Valparaíso, 1928.

Congreso Nacional, Diario de Sesión Cámara de Diputados: 13 de diciembre de 1960, Biblioteca del Congreso Nacional, Valparaíso, 1960.

Congreso Nacional, Diario de Sesión Cámara de Diputados: 14 de diciembre de 1960, Biblioteca del Congreso Nacional, Valparaíso, 1960.

Congreso Nacional, Diario de Sesión Cámara de Diputados: 30 de noviembre de 1965, Biblioteca del Congreso Nacional, Valparaíso, 1965.

Diputado Gustavo Lorca, "Homenaje a la ex presidenta de la Corte de Apelaciones de Valparaíso, señora Fanny Leibovich Guberman”, Diario de Sesión Cámara de Diputados: 20 de junio de 1972, Diario oficial de la República de Chile, Santiago, 1972.

Ministerio de Justicia, Ley N4.447: 23 de octubre de 1928, Biblioteca del Congreso Nacional, Santiago, 1928. Disponible en: https://www.leychile.cl/Navegar?idNorma=24742. [Fecha de consulta: 16 de agosto de 2020]

Ministerio de Justicia, Decreto $N^{\circ} 2.531$ : 24 de diciembre de 1928, Diario Oficial de la República de Chile, Santiago, 1928. Disponible en: https://www.bcn.cl/obtienearchivo? id=recursoslegales/10221.3/32863/DTO_2531.pdf. [Fecha de consulta: 16 de agosto de

Ministerio de Justicia, Ley N ${ }^{\circ} 14.550: 3$ de marzo de 1961, Biblioteca del Congreso Nacional, Santiago, 1961. Disponible en: https://www.leychile.cl/Navegar?idNorma=27761. [Fecha de consulta: 16 de agosto de 2020]

Corte Suprema de Justicia, Escalafones del Poder Judicial, Biblioteca de la Corte Suprema,

Biblioteca de la Corte Suprema, Colección Corte de Apelaciones de Santiago, Santiago de

Poder Judicial, Secretaría Técnica Igualdad de Género y No Discriminación, “Mujeres y hombres en números en el Poder Judicial", Portal Secretaría de Género del Poder Judicial. Disponible en: http://secretariadegenero.pjud.cl/index.php/mujeres-y-hombres-ennumeros-en-el-poder-judicial. [Fecha de consulta: 16 de agosto de 2020] 


\section{BIBLIOGRAFÍA}

Albornoz, María Eugenia, “La Justicia, el sentimiento y el sentir. Usos y declinaciones del verbo en pleitos por injuria en Chile, 1670-1870", en Albornoz, María Eugenia (coord.), Sentimientos y Justicia. Coordenadas emotivas de experiencias judiciales. Chile, 1650-1990, Acto Editores, Santiago, 2016, pp. 60-93.

Azócar, María José, "Expertos en derecho: profesión legal, género y reformas judiciales en Chile", Revista de Derecho, Valdivia, vol. XXVIIII, № 2, 2015, pp. 9-29.

Azócar, María José, “¿Cómo se construye la experticia judicial?: Una etnografía judicial en tribunales de familia de Santiago de Chile”, Revista de Derecho, Valdivia, vol. XXXI, no 2, 2018, pp. 9-27.

Biernat, Carolina \& Queirolo, Graciela, "Presentación del Dossier: Mujeres, profesiones y procesos de profesionalización en la Argentina y Brasil", Anuario del Instituto de Historia Argentina, Buenos Aires, vol. 18, n¹, 2018. Disponible en: https://doi.org/10.24215/2314257Xe060. [Fecha de consulta: 16 de agosto de 2020]

Casas, Lidia, El funcionamiento de los nuevos tribunales de familia: resultados de una investigación exploratoria, Facultad de Derecho de la Universidad Diego Portales, Santiago, 2006. 27 p. Disponible en: http://biblioteca.cejamericas.org/bitstream/handle/2015/1063/ InformeTribunalesdeFamilia.pdf?sequence=1\&isAllowed=y. [Fecha de consulta: 16 de agosto de 2020]

Dirección de Estudios de la Corte Suprema, Igualdad de género y no discriminación. Proyecto de Estudio Diagnóstico de la perspectiva de Igualdad de Género en el Poder Judicial Chileno, Management \& Research Chile, Santiago, 2015-2016. 132 p. Disponible en: http://secretariadegenero.pjud.cl/ index.php/2-central/28-estudio-genero-poder-judicial-chile. [Fecha de consulta: 16 de agosto de 2020]

Errázuriz, Javiera, “Las juezas/madres. Una historia de la feminización de la Justicia de menores en Chile, 1928-1968”, Intus Legere Historia, Santiago, vol. 13, nº 1, 2019, pp. 161-183.

Fuentes, Claudio, "Los dilemas del juez de familia", Revista Chilena de Derecho, Santiago, vol. 42, no3, 2015, pp. 935-965.

Gajardo, Samuel, El Problema de la Protección a la infancia y su estado actual en Chile, Folleto de Divulgación, Editorial Chile, Santiago, 1940. 21 p.

Gajardo, Samuel, Justicia con Alma, Imprenta Dirección General de Prisiones, Santiago, 1936. 337 p.

Gajardo, Samuel, Los derechos del niño y la tiranía del ambiente, Imprenta Nascimento, Santiago, 1929. $179 \mathrm{p}$.

Gajardo, Samuel, Memorias de un juez, Santiago, 1957.130 p.

González Le Saux, Marianne, "Lawyers' Diversity and the Limits of Fraternity”, en The Rule of Lawyers: The Politics of the Legal Profession and Legal Aid in Chile, 1915-1964, Ph. D. Dissertation, Columbia University, Nueva York, 2018. 549 p.

González, Maricela, “Asistentes sociales y salud pública en Chile: Identidad profesional y lucha gremial, 1925-1973”, Dynamis, Granada, vol. 37, n², 2017, pp. 345-365.

Illanes, María Angélica, Cuerpo y sangre de la política. La construcción histórica de las visitadoras sociales (1887-1940), LOM, Santiago, 2006. 498 p. 
Kennedy, Duncan, “Three Globalizations of Law and Legal Thought: 1850-2000”, en Trubek, David y Santos, Álvaro (Eds.), The New Law and Economic Development. A Critical Appraisal, Cambridge University Press, 2006, pp. 19-73.

Lagrave, Rose-Marie, “Una emancipación bajo tutela. Educación y trabajo de las mujeres en el s. XX”, en Duby George \& Perrot, Michelle (Dir.), Historia de las mujeres en Occidente, Tomo 5, Taurus, Barcelona, 1993, pp. 465-508.

Nash, Mary, "Identidades de género, mecanismos de subalternidad y procesos de emancipación femenina”, Revista CIDOB d’ Afers Internacionals, Barcelona, n73-74, 2006, pp. 39-57.

Olsen, Frances, “El sexo del derecho”, en. Ruiz, Alicia E. C. (Comp.), Identidad femenina y discurso jurídico, Editorial Biblos, Buenos Aires, 2000, pp. 137-156.

Perrot, Michelle, "Qu'est-ce qu'un mètier de femme", Le Mouvement social, Paris, n 140, 1987, pp. 3-8.

Rojas, Jorge, Historia de la infancia en el Chile Republicano, Tomo I, Ediciones de la JUNJI, Santiago, 2016. $830 \mathrm{p}$.

Scott, Joan, "La mujer trabajadora en el siglo XIX”, en Duby, George \& Perrot, Michelle (Dir.), Historia de las mujeres, Tomo 4, Taurus, Barcelona, 1993, pp. 405-436.

Schonhaut, Lucía, "Profilaxia del abandono. Cien años de protección de la infancia en Chile", Revista Chilena de Pediatría, vol. 18, n4, 2010, pp. 304-312.

Wikander, Ulla, De criada a empleada. Poder, sexo y división del trabajo (1789-1950), Siglo XXI, Madrid, 2016. $192 \mathrm{p}$.

Zárate, Soledad \& Godoy, Lorena, “Análisis crítico de los estudios históricos del trabajo femenino en Chile”, en Cuadernos de Investigación, Santiago, n², Centro de Estudios de la Mujer, 2005. 49 p.

\section{NOTAS}

1. Scott, Joan, "La mujer trabajadora en el siglo XIX", en Duby, George \& Perrot, Michelle (Dir.), Historia de las mujeres, Tomo 4, Taurus, Barcelona, 1993, p. 427.

2. Zárate, Soledad \& Godoy, Lorena, “Análisis crítico de los estudios históricos del trabajo femenino en Chile", en Cuadernos de Investigación № 2, CEM, Santiago, 2005, p. 6.

3. Wikander, Ulla, De criada a empleada. Poder, sexo y división del trabajo (1789-1950), Siglo XXI, Madrid, 2016, p. 51.

4. Biernat, Carolina \& Queirolo, Graciela, “Mujeres, profesiones y procesos de profesionalización en la Argentina y Brasil", Anuario del Instituto de Historia Argentina, Buenos Aires, vol. 18, $\mathrm{n}^{\circ} 1$, 2018, p. 3.

5. Nash, Mary, "Identidades de género, mecanismos de subalternidad y procesos de emancipación femenina”, Revista CIDOB d' Afers Internacionals, Barcelona, $n^{\circ}$ 73-74, 2006, p. 43.

6. Biernat, C. \& Queirolo, G., “Mujeres, profesiones y procesos”, Op. Cit., p. 2.

7. Perrot, Michelle, "Qu'est-ce qu'un mètier de femme", Le Mouvement social, Paris, $\mathrm{n}^{\circ}$ 140, 1987, p. 3. Biernat y Queirolo usan el concepto de desjerarquización para referirse a la pérdida de prestigio de un oficio o profesión, o espacio intraprofesional.

8. Olsen, Frances, "El sexo del derecho" en Identidad femenina y discurso jurídico, compilado por Alicia E. C. Ruiz, Editorial Biblos, Buenos Aires, 2000, p. 13

9. González Le Saux, Marianne, "Lawyers' Diversity and the Limits of Fraternity", en The Rule of Lawyers: The Politics of the Legal Profession and Legal Aid in Chile, 1915-1964, Ph.D. Dissertation, Columbia University, Nueva York, 2018, p. 320. 
10. Olsen, Frances, “El sexo del derecho", Op. Cit., pp. 16-17

11. Actas Primer Congreso Nacional de Protección de la Infancia, Imprenta Barcelona, Santiago de Chile, 1913, pp. 392.

12. Schonhaut, Lucía, "Profilaxia del abandono. Cien años de protección de la infancia en Chile, Revista Chilena de Pediatría, vol. 18, núm. 4, 2010, pp. 306.

13. Rojas, Jorge, "Los Derechos del Niño en Chile: Una Aproximación Histórica, 1910-1930", HISTORIA, 2007, 40 (1), p. 136-137.

14. Kennedy, Duncan, "Three Globalizations of Law and Legal Thought: 1850-2000", en David Trubek y Alvaro Santos (eds), The New Law and Economic Development. A Critical Appraisal, Cambridge University Press, 2006, pp. 38-39.

15. Kennedy, "Three Globalizations of, Op. Cit., pp. 44.

16. Kennedy, "Three Globalizations of, Op. Cit., pp. 51

17. Ministerio de Justicia, Ley $N^{\circ}$ 4.447: 23 de octubre de 1928, Biblioteca del Congreso Nacional, Santiago, 1928, https://www.leychile.cl/Navegar?idNorma=24742, consultado el 17 de agosto de 2019.

18. Para más datos sobre las primeras juezas y su distribución en el Poder Judicial, ver Errázuriz, Javiera, "Las juezas/madres. Una historia de la feminización de la Justicia de menores en Chile, 1928-1968”, Intus Legere Historia, Santiago, vol. 13, nº 1, 2019, p. 161-183.

19. Fanny Leibovich fue nombrada Ministra de la Corte de Apelaciones de Valparaíso en 1971, y al año siguiente, llegó a ser Presidenta de esa misma Corte, siendo así la primera mujer Presidente de Corte de Apelación del país. Leibovich también fue la primera profesora de la Escuela de Derecho de la Universidad de Chile, sede Valparaíso (hoy Universidad de Valparaíso).

20. Diputado Gustavo Lorca, "Homenaje a la ex presidenta de la Corte de Apelaciones de Valparaíso, señora Fanny Leibovich Guberman”, en Diario de Sesión Cámara de Diputados: 20 de junio de 1972, Diario Oficial de la República de Chile, Santiago, 1972.

21. El resto de la documentación está extraviada, como señalaron en la Biblioteca de la Corte Suprema y en el Archivo Judicial de Santiago.

22. Congreso Nacional, Diario de Sesiones del Senado: 23 de noviembre de 1927, Biblioteca del Congreso Nacional, Valparaíso, 1927, p. 131.

23. Diputado Guillermo Azócar, "Intervención", en Congreso Nacional, Diario de Sesiones del Senado: 11 de junio de 1928, Biblioteca del Congreso Nacional, Valparaíso, 1928, p. 165.

24. Ley 4.447, 23 de octubre de 1928. El reglamento en cuestión establecía, en su artículo 20, que "los Jueces de Menores deberán acreditar su preparación y conocimientos de psicología mediante un examen oral y escrito rendido ante una comisión formada por el Director General de Protección de Menores, el Director del Politécnico Elemental de Menores "Alcibíades Vicencio" y el Director del Laboratorio de Psicología Experimental del Instituto Pedagógico. La Comisión podrá eximir del examen a los candidatos que acrediten sus conocimientos mediante trabajos originales que estime suficientes". Véase Ministerio de Justicia, Decreto $N^{\circ} 2.531: 24$ de diciembre de 1928, Diario Oficial de la República de Chile, Santiago, 1928, https://www.bcn.cl/obtienearchivo? id=recursoslegales/10221.3/32863/DTO_2531.pdf, consultado el 16 de agosto de 2019.

25. Rojas, Jorge, Historia de la infancia en el Chile Republicano, Tomo I, Ediciones de la JUNJI, Santiago, 2016, p. 387.

26. Rojas, J., Historia de la infancia, Op. Cit., p. 387.

27. El discernimiento existía en la legislación "adulta", y podía actuar como eximente de culpa en determinados casos.

28. Rojas, J., Historia de la infancia, Op. Cit., p. 388.

29. Gajardo, Samuel, Justicia con Alma, Imprenta Dirección General de Prisiones, Santiago, 1936, p.

52.

30. Gajardo, Samuel, Los derechos del niño y la tiranía del ambiente, Imprenta Nascimento, Santiago, 1929, p. 37 
31. Albornoz, María Eugenia, "La Justicia, el sentimiento y el sentir. Usos y declinaciones del verbo en pleitos por injuria en Chile, 1670-1870", en Albornoz, María Eugenia (coord.), Sentimientos y Justicia. Coordenadas emotivas de experiencias judiciales. Chile, 1650-1990, Acto Editores, Santiago, 2016, p. 72.

32. Albornoz, M. E., "La Justicia, el sentimiento", Op. Cit., p. 72.

33. Gajardo, Samuel, Memorias de un juez, Santiago, 1957, p. 12.

34. Gajardo, Samuel, El Problema de la Protección a la infancia y su estado actual en Chile, Folleto de Divulgación, Editorial Chile, Santiago, 1940.

35. Olsen, Frances, "El sexo del derecho", Op. Cit., pp. 17

36. El primer Tribunal de Menores de Valparaíso se funda en 1934; el segundo se fundaría en 1964.

37. Ministerio de Justicia, Ley $N^{\circ}$ 14.550: 3 de marzo de 1961, Biblioteca del Congreso Nacional, Santiago, 1961, https://www.leychile.cl/Navegar?idNorma=27761, consultado el 17 de agosto de 2019.

38. Ministerio de Justicia, Ley $N^{\circ} 14.550$, Op. Cit.

39. Congreso Nacional, Diario de Sesión Cámara de Diputados: 13 de diciembre de 1960, Biblioteca del Congreso Nacional, Valparaíso, 1960, p. 1189.

40. Congreso Nacional, Diario de Sesión, Op. Cit., p. 1189.

41. Sobre el tema ver Illanes, María Angélica, Cuerpo y sangre de la política. La construcción histórica de las visitadoras sociales (1887-1940), LOM, Santiago, 2006 y González, Maricela, "Asistentes sociales y salud pública en Chile: Identidad profesional y lucha gremial, 1925-1973”, Dynamis, Granada, vol. 37, n 2, 2017, p. 345-365.

42. Congreso Nacional, Diario de Sesión Cámara de Diputados: 14 de diciembre de 1960, Biblioteca del Congreso Nacional, Valparaíso, 1960, p. 1271.

43. Congreso Nacional, Diario de Sesión Cámara de Diputados: 30 noviembre de 1965, Biblioteca del Congreso Nacional, Valparaíso, 1965, p. 1849.

44. Gonzalez Le Saux, Marianne, "Legal Aids, Social Workers, and the redefinition of the Legal Profession in Chile, 1925-1960", Law \& Social Inquiry, Vol. 42, n², Spring 2017, p. 366

45. Resulta interesante pensar cómo sería la relación laboral entre visitadoras y juezas de menores, cuál de ellas realizaría las tareas consideradas como femeninas, cómo se resuelve esa jerarquía y división de competencias que hemos mencionado en el caso de la SAJ.

46. Lagrave, Rose-Marie, "Una emancipación bajo tutela. Educación y trabajo de las mujeres en el s. XX”, en Duby, G. \& Perrot, M. (Dir.), Historia de las mujeres, Op. Cit., p. 507.

47. González Le Saux, M., “Lawyers' Diversity”, Op. Cit., p. 322.

48. González Le Saux, M., “Lawyers' Diversity”, Op. Cit., p. 325.

49. González Le Saux, M., “Lawyers' Diversity”, Op. Cit., p. 327.

50. En este apartado nos aproximaremos hacia comienzos del siglo XXI, por lo que usaremos la terminología actual -“derecho de familia”- para referirnos a lo que previamente se denominaba justicia de menores.

51. Dirección de Estudios de la Corte Suprema, Igualdad de género y no discriminación. Proyecto de Estudio Diagnóstico de la perspectiva de Igualdad de Género en el Poder Judicial Chileno, Management \& Research Chile, Santiago, 2015-2016, p. 52-53, http://secretariadegenero.pjud.cl/index.php/2central/28-estudio-genero-poder-judicial-chile, consultado el 3 de marzo de 2020.

52. Dirección de Estudios de la Corte Suprema, Igualdad de género, Op. Cit., p. 53.

53. Azócar, María José, "Expertos en derecho: profesión legal, género y reformas judiciales en Chile", Revista de Derecho, Valdivia, vol. XXVIIII, no 2, 2015, p. 10.

54. Casas, Lidia, El funcionamiento de los nuevos tribunales de familia: una investigación exploratoria, Facultad de Derecho de la Universidad Diego Portales, Santiago, 2006, p. 4., http:// biblioteca.cejamericas.org/bitstream/handle/2015/1063/InformeTribunalesdeFamilia.pdf? sequence=1\&isAllowed=y, consultado el 15 de septiembre de 2019 . 
55. Casas, L., El funcionamiento, Op. Cit., p. 7.

56. Azócar, M. J., "Expertos en derecho”, Op. Cit., p. 21.

57. Azócar, M. J., “Expertos en derecho”, Op. Cit., p. 21.

58. Fuentes, Claudio, "Los dilemas del juez de familia”, Revista Chilena de Derecho, Santiago, vol. 42, no 3, 2015, p. 959.

59. Fuentes, C., "Los dilemas", Op. Cit., p. 958.

60. Azócar, María José, “¿Cómo se construye la experticia judicial?: Una etnografía judicial en tribunales de familia de Santiago de Chile", Revista de Derecho, Valdivia, vol. XXXI, no 2, 2018, p. 10. 61. Azócar, M. J., “¿Cómo se construye?”, Op. Cit., p. 13-14.

\section{RESÚMENES}

En los 40 años que van entre 1928 y 1968, los tribunales de menores vivieron un proceso de feminización al aumentar la cantidad abogadas que trabajan en ellos. En 1968, por ejemplo, los 9 tribunales de menores que existían en el país estaban encabezados por juezas y secundados por secretarias de juzgado. Sin embargo, postulamos que la feminización de la Justicia de Menores trajo consigo una desvaloración de este espacio de justicia, al producirse una asociación con características como la afectividad, la emotividad y la comprensión, consideradas como parte de la naturaleza femenina. De este modo, esta vinculación con la emoción y lo femenino hizo que la justicia de menores fuera menos valorada en el contexto profesional.

In the 40 years between 1928 and 1968, Chile's juvenile courts underwent a process of feminization as the number of female legal professionals working in them increased. By 1968, the country's nine juvenile courts were headed by female judges and seconded by female judicial assistants. This article argues that the feminization of the Juvenile Justice system resulted in a devaluation of its professional status, because it was associated with characteristics considered to be feminine, such as sensitivity, emotionality and understanding. These character traits, seen as necessary for the courts and natural for women, meant that Juvenile Justice was perceived as less intellectually challenging than other areas of the law.

Au cours des quarante années qui vont de 1928 à 1968, les tribunaux pour mineurs ont connu un processus de féminisation, le nombre de femmes travaillant dans ces tribunaux ayant augmenté. En 1968, par exemple, les neuf tribunaux pour mineurs du pays étaient dirigés par des femmes juges secondées par des femmes secrétaires de tribunal. Cependant, nous postulons que la féminisation de la justice pour mineurs a entraîné une dévaluation de cet espace de justice, car il s'est retrouvé associé à des caractéristiques telles que l'affectivité, l'émotion et la compréhension, considérées comme féminines. Ainsi, ce lien entre émotion et féminin a dévalorisé la justice des mineurs dans le contexte professionnel. 


\section{ÍNDICE}

Mots-clés: feminisation, devalorisation, justice pour mineurs, femmes professionnelles, Santiago du Chili, 1928-1968

Palabras claves: feminización, desvalorización, Justicia de Menores, mujeres profesionales, Santiago de Chile, 1928-1968

Keywords: feminization, devaluation, Juvenile Justice, professional women, Santiago de Chile, 1928-1968

\section{AUTORES}

\section{JAVIERA ERRÁZURIZ TAGLE}

Dra. en Historia Contemporánea, Universidad Autónoma de Madrid/ Pontificia Universidad Católica de Chile. Académica Licenciatura en Historia, Facultad de Educación y Ciencias Sociales, Universidad Andrés Bello.

javiera.errazuriz@unab.cl

Este artículo se realizó en el contexto del proyecto Fondecyt de Iniciación n¹1170662. Aporta nuevas fuentes y nuevos enfoques a lo presentado en Errázuriz Javiera, "Las juezas/madres. Una historia de la feminización de la Justicia de menores en Chile, 1928-1968”, Intus Legere Historia, vol. 13, nº1, 2019, pp. 161-183.

\section{NICOLÁS PIZARRO HUERTA}

Magíster en Historia, Pontificia Universidad Católica de Valparaíso, ayudante de investigación proyecto Fondecyt de Iniciación n¹1170662. 